\title{
Inhibition of cyclooxygenase-2 by tetramethylpyrazine and its effects on A549 cell invasion and metastasis
}

\author{
CHUN-YAN ZHENG ${ }^{1}$, WEI XIAO ${ }^{1}$, MAO-XIANG ZHU ${ }^{2}$, XIU-JIE PAN ${ }^{2}$, ZHI-HUA YANG ${ }^{2}$ and SHENG-YU ZHOU $^{1}$ \\ ${ }^{1}$ Department of Respiratory Medicine, Qilu Hospital, Shandong University, Jinan 250012; \\ ${ }^{2}$ Institute of Radiation Medicine, Academy of Military Medical Sciences, Beijing 100850, P.R. China
}

Received November 23, 2011; Accepted January 25, 2012

DOI: 10.3892/ijo.2012.1375

\begin{abstract}
Cyclooxygenase (COX)-2 plays an important role in tumorigenesis and has been implicated to be a critical factor for invasion and metastasis of lung cancer. Tetramethylpyrazine (TMP), an effective component of the traditional Chinese medicine Chuanxiong, has been traditionally used in treating neurovascular and cardiovascular diseases. Recently TMP has been reported to have beneficial effect in cancer patients. However, the function and the mechanism of TMP in lung cancer have not been elucidated to date. In this study, we investigated the in vitro and in vivo effect of TMP in tumorigenesis and whether COX-2 is a molecular target of TMP. We showed that TMP exhibited a dose- and time-dependent inhibition on A549 cell proliferation by suppressing cell cycle progression. In vitro treatment of A549 cells with TMP resulted in a significant inhibition of invasion, associated with reduced activities of COX-2 and MMP-2/TIMP-2. Furthermore, in vivo experiments showed that TMP significantly suppressed metastatic growth of A549 cells and COX-2 expression in metastatic nude mouse model. This preclinical study provides the first evidence for the novel anti-tumor effects of TMP as a COX-2 pathway inhibitor in human adenocarcinoma cell line A549. These studies suggest that TMP may serve as an effective agent for the treatment and chemoprevention of non-small cell lung cancer.
\end{abstract}

\section{Introduction}

Lung cancer is a major cause of malignancy-related deaths worldwide (1) and its incidence is rising in many countries. Non-small cell lung cancers (NSCLC), including adenocarcinomas, constitute the majority of lung cancers (75-80\%). In many cases, local invasion and/or metastasis to distant organs have already occurred by the time of diagnosis. Invasion and metastasis are major causes of treatment failure in patients with lung adenocarcinoma. Tumor metastasis is a complex, multistep

Correspondence to: Dr Wei Xiao, Department of Respiratory Medicine, Qilu Hospital, Shandong University, Jinan 250012, P.R. China

E-mail: xiaowei4226@163.com

Key words: tetramethylpyrazine, lung cancer, metastasis, invasion process that depends on the characteristics of the tumor and its host organs. Understanding the molecular targets involved and their corresponding inhibitors will provide promising new approaches for the treatment of cancer.

Cyclooxygenase $(\mathrm{COX})$ is the rate-limiting enzyme for the production of eicosanoid prostaglandins (PGs) and thromboxanes (TXs) from free arachidonic acid. Three forms of COX have now been described (2-4). These isoenzymes are differentially regulated and exhibit distinct functions. COX-1 is constitutively expressed in most cells and tissues, and is important for maintaining homeostatic function. In contrast, COX-2 is an inducible isoenzyme that acts as an immediate early gene expressed in response to growth factors, cytokines, and other stimuli (2). Several studies have demonstrated a constitutive upregulation of COX-2 expression in human NSCLC (5-7). Recently, increasing amount of evidence suggests a multi-faceted role of COX-2 in promoting the malignant phenotype of lung cancer, including inhibition of apoptosis $(8,9)$, increased angiogenesis $(10,11)$, decreased host immunity (12), enhanced invasion and metastasis $(13,14)$. Furthermore, several studies have indicated that COX-2 may be a central element in the process of lung cancer invasion and metastasis $(5,15-17)$.

Due to the critical role of COX-2 in carcinogenesis, considerable interest has been focused on COX-2 inhibitors as a chemopreventive strategy. Both isoenzymes can be inhibited by non-steroidal anti-inflammatory drugs (NSAIDs) including the non-selective COX inhibitors and selective COX-2 inhibitors. Although the pharmacological action of NSAIDs have demonstrated efficacy, the adverse effects such as gastrointestinal bleeding (18) or increased cardiovascular risk (19) have limited their widespread usage. Thus, immense effort has been devoted to developing molecules that can potently inhibit COX-2 with fewer side effects.

Tetramethylpyrazine (TMP), a bioactive constituent of the traditional Chinese medicinal herb Ligusticum chuanxiong, has been applied in the treatment of neurovascular and cardiovascular diseases in the clinic $(20,21)$. The underlying mechanism includes augmentation of organ blood volume, inhibition of platelet aggregation, suppression of apoptosis, and protection against free radicals. In the past decade, TMP has been found to influence some aspects of lung cancer such as invasion and metastasis beyond its traditional roles $(22,23)$. However, little information is known about the cellular and molecular mechanisms involved. Wan et al (24) reported that TMP has the pharmacological effect 
of inhibiting lipopolysaccharide-induced expression of COX-2 in macrophages and the apoptosis of cardiac myocytes in sucking mice, but does not influence the activity of COX-2. Zhang and coworkers (25) reported that TMP can reduce the expression levels of COX-2 in rats with acute pulmonary thromboembolism and alleviate the inflammatory reaction. However, whether TMP has any function on COX-2 in pulmonary tumors has not yet been reported. We postulate that COX-2 might be an important mechanism involved in the effect of TMP in lung cancer. Here, we investigated whether TMP inhibited NSCLC growth, invasion and metastasis by targeting COX-2 pathway. For this study, we used the peripheral airway-derived adenocarcinoma cell line A549, because adenocarcinoma is currently the most common form of lung cancer and COX-2 levels are significantly higher in adenocarcinomas than in squamous cell carcinomas (26). For a positive control we used the non-selective COX inhibitor indomethacin, which has been proven to inhibit COX-2 activity and expression in NSCLC cells $(27,28)$.

\section{Materials and methods}

Cell culture and reagents. Both the human lung adenocarcinoma cell line A549 and primary normal human lung fibroblasts (NHLFs) were obtained from American Type Culture Collection (ATCC, USA) and cultured in DMEM (Gibco, USA) supplemented with $10 \%(\mathrm{v} / \mathrm{v})$ heat-inactivated fetal bovine serum (FBS) (Hyclone), $100 \mathrm{U} / \mathrm{ml}$ penicillin, and $100 \mu \mathrm{g} / \mathrm{ml}$ streptomycin at $37^{\circ} \mathrm{C}$ in a humidified atmosphere of $5 \% \mathrm{CO}_{2} / 95 \%$ air.

TMP was obtained in sterile $20 \mathrm{mg} / \mathrm{ml}$ injection ampules from Beijing Yong Kang Pharmaceutical Co. (Beijing, China). This preparation was confirmed to be homogeneous by thinlayer chromatography. The COX inhibitor indomethacin was purchased from Sigma Chemicals.

In vitro cell proliferation assay. Cell proliferation was measured by a 3-(4,5-dimethylthiazol-2-yl)-2,5-diphenyltetrazolium bromide assay (MTT) following the manufacturer's instructions. A549 cells $\left(3 \times 10^{3}\right.$ cells/well) were plated in 96-well microtiter plates (Costar 3596, Corning) and incubated overnight. The next day, cells were then treated with either $1 \%$ serum DMEM as a control or various concentrations of TMP in 1\% serum DMEM for 24,48 , or $72 \mathrm{~h}$, respectively. At the end of the assay time-point, $20 \mu \mathrm{l}$ of a $5 \mathrm{mg} / \mathrm{ml}$ solution of MTT (Sigma, USA) dissolved in PBS was added to each well and the cells were further incubated at $37^{\circ} \mathrm{C}$ for $4 \mathrm{~h}$. Cells were lysed in $150 \mu \mathrm{l}$ DMSO and absorbance was measured at $570 \mathrm{~nm}$. Six replicate wells were used for each analysis, and data from replicate wells are presented as means with $95 \%$ confidence intervals. At least three independent experiments were performed.

Flow cytometry fluorescence-activated cell sorting analysis. A549 cells $\left(1 \times 10^{6}\right)$ were treated with different concentrations of TMP (200, 400 and $800 \mu \mathrm{g} / \mathrm{ml}$, respectively) or $200 \mu \mathrm{M}$ indomethacin (IN) for $72 \mathrm{~h}$ and then collected. The percentages of the cell population at $G_{0}-G_{1}, S$ and $G_{2}-M$ phases were determined with a fluorescence-activated cell sorting (FACS) flow cytometer (BD Sciences) after propidium iodide staining.

Invasion assay. The invasion assay was carried out using 24-well transwell cell culture chambers (Corning, Cambridge, MA). The
8.0- $\mu \mathrm{m}$ pore size upper chambers were coated with growth factor-reduced Matrigel (Becton-Dickinson Labware, Bedford, MA). After incubation in serum-free DMEM for $24 \mathrm{~h}$, A549 cells in log-phase growth were detached by trypsin and resuspended in DMEM with $1 \%$ fetal bovine serum. Subsequently, $4 \times 10^{4}$ cells were plated in the upper chamber in both the control and the $200 \mu \mathrm{g} / \mathrm{ml}$ TMP group. DMEM supplemented with $10 \%$ fetal bovine serum was added in the lower chamber as a chemoattractant. Following a $24-\mathrm{h}$ incubation at $37^{\circ} \mathrm{C}$ in a humidified $5 \% \mathrm{CO}_{2}$ atmosphere, the cells in the upper chamber and on the Matrigel were mechanically removed with a cotton swab. The cells adherent to the outer surface of the membrane were fixed with methanol and stained with $0.2 \%$ crystal violet stain. The invading cells were examined, counted, and photographed by microscopy at magnifications $x 50$. Six fields were counted per filter in each group, and the experiment was repeated five independent times.

Measurement of MMP-2/TIMP-2 activity. The activity of MMP-2/TIMP-2 was measured by commercially available assay kits (human MMP-2/TIMP-2 complex DuoSet, R\&D Systems, USA). A549 cells were incubated with various concentrations of TMP $(200,400$ and $800 \mu \mathrm{g} / \mathrm{ml})$ or $200 \mu \mathrm{M}$ indomethacin (IN) for $24 \mathrm{~h}$ at $37^{\circ} \mathrm{C}$ in a humidified $5 \% \mathrm{CO}_{2}$ atmosphere. The resultant culture supernatants were collected and measured for MMP-2/TIMP-2 activity by ELISA according to the manufacturer's instructions. All measurements were made in triplicate and repeated in at least three separate experiments.

Measurement of $P G E_{2}$ levels. As an indicator of COX activity, the accumulation of $\mathrm{PGE}_{2}$ in the culture medium was measured by specific radioimmunoassay (RIA). Culture medium from each treatment group was collected after a 24-h incubation. The extract was resuspended in RIA buffer and immunoreactive $\mathrm{PGE}_{2}$ determined (Puerweiye Biotechnology Co. Ltd., Beijing, China).

Western blot analysis for $C O X-1$ and $C O X-2$ expression. The cells from each treatment group were lysed at $4^{\circ} \mathrm{C}$ for $15 \mathrm{~min}$ in lysis buffer [50 mM Tris $\mathrm{pH} 8.0,150 \mathrm{mM}$ sodium chloride, $1 \mathrm{mM}$ ethylenediamine tetraacetic acid (EDTA), $1 \%$ Nonidet P-40, $0.5 \%$ sodium deoxycholate, $0.1 \%$ sodium dodecyl sulfate (SDS), $1 \mathrm{mM}$ phenylmethylsulfonyl fluoride (PMSF), complete protease inhibitor cocktail tablets (Roche, Mannheim, Germany)]. The cell lysates were centrifuged at 13,000 rpm for $10 \mathrm{~min}$ and the supernatant collected. Total protein from cell lysates were measured with a protein assay reagent (Bio-Rad), and $50 \mu \mathrm{g}$ was separated on $10 \%$ SDS-polyacrylamide gels. Following separation, the proteins were transferred to Hybond nitrocellulose membranes (Amersham Pharmacia Biotech) and the filters probed with anti-human COX-1 antibody (R\&D) and anti-human COX-2 antibody (Cayman Chemical). The membranes were developed by the ECL chemiluminescence system (Amersham Pharmacia Biotech) and exposed to X-ray film (Fujifilm, Fuji Medical Systems Inc., Stamford, CT). Equal loading of samples was confirmed by probing the membranes with a $\beta$-actin antibody.

COX-2 activity assay. The COX-2 activity was measured according to the manufacturer's instructions. Briefly, following 
Table I. TMP arrests cell cycle progression in A549 cells.

\begin{tabular}{lcccrr}
\hline Population $(\%)$ & CON & TMP200 & TMP400 & TMP800 & IN \\
\hline $\mathrm{G}_{0} / \mathrm{G}_{1}$ phase & $55.06 \pm 1.44$ & $56.24 \pm 1.92$ & $69.22 \pm 1.62^{\mathrm{a}}$ & $72.61 \pm 1.42^{\mathrm{a}}$ & $74.56 \pm 9.37^{\mathrm{a}}$ \\
$\mathrm{S}$ phase & $34.52 \pm 4.15$ & $36.02 \pm 2.36$ & $22.83 \pm 1.94^{\mathrm{a}}$ & $18.22 \pm 2.05^{\mathrm{a}}$ & $19.95 \pm 7.18^{\mathrm{a}}$
\end{tabular}

${ }^{\mathrm{a}} \mathrm{p}<0.05$ versus control. CON, control; IN, indomethacin at $200 \mu \mathrm{M}$.

a 24-h incubation at $37^{\circ} \mathrm{C}$ in a humidified $5 \% \mathrm{CO}_{2}$ atmosphere, A549 cells $\left(1 \times 10^{7}\right)$ from each treatment group were collected by centrifugation $\left(2,000 \times \mathrm{g}\right.$ for $10 \mathrm{~min}$ at $\left.4^{\circ} \mathrm{C}\right)$. The cell pellet was sonicated in cold lysis buffer $(100 \mathrm{mM}$ Tris-HCl, $\mathrm{pH} 7.5$ containing protease inhibitors) and centrifuged at $10,000 \mathrm{x}$ g for $15 \mathrm{~min}$ at $4^{\circ} \mathrm{C}$. The supernatant was then removed and stored at $-80^{\circ} \mathrm{C}$ for later assay with the commercially available COX activity assay kit (Cayman Chemicals).

Experimental lung metastasis assay in nude mice. For experimental lung metastasis assay, A549 cells $\left(5 \times 10^{5}\right.$ in a volume of $0.2 \mathrm{ml}$ serum-free DMEM medium) were injected into the lateral tail veins of 18-week-old female BALB/c nude mice (Laboratory Animal Center of the Academy of Military Medical Science, Beijing, China). The BALB/c nude mice were divided into two groups with ten mice per group. Mice in TMP group were given intraperitoneal injections of TMP (100 mg/ $\mathrm{kg} /$ day $)$ daily, and mice in control group received intraperitoneal injections of isovolume physiological saline daily. The diet and mental status of the mice were observed every day, and body weight was measured every 4 days. The animals were sacrificed at 29 days after the injection of tumor cells. The number of metastases in the lung surface was counted by visual inspection after staining the lung with Bouin's solution. Right lobes of the lung tissues were sectioned, fixed in $10 \%$ formalin $(\mathrm{pH} 7.4)$ and subjected to H\&E histological staining to evaluate the presence or absence of tumors. These experiments were repeated to confirm the results. This animal study was approved by the Institutional Animal Care and Use Committee of China, and institutional guidelines for animal welfare and experimental conduct were followed.

Immunohistochemical staining of $C O X-2$. The dissected lung tissues were prepared for immunohistochemical analysis of COX-2 localization. Four-micrometer sections of formalin-fixed, paraffin-embedded tissue were cut onto silanized glass slides, deparaffinized with xylene for $10 \mathrm{~min}$ three times and rehydrated through a graded alcohol bath. The deparaffinized sections were heated and boiled twice for $10 \mathrm{~min}$ in $10 \mathrm{mM}$ citrate buffer (pH 6.0) for antigen retrieval. To diminish non-specific staining, each section was treated with $3 \%$ hydrogen peroxide in methanol for $10 \mathrm{~min}$. For the detection of COX-2, slides were incubated with 1:50 \pm 100 dilutions of the monoclonal mouse anti-COX-2 antibody (Cayman Chemical) at $4^{\circ} \mathrm{C}$ overnight in PBS, containing $1 \%$ BSA and $0.05 \%$ Tween-20. The sections were then washed in PBS and incubated with the secondary antibody for $30 \mathrm{~min}$ at $37^{\circ} \mathrm{C}$. After being soaked in HRP substrate buffer for $10 \mathrm{~min}$, the slides were incubated with DAB solution until brown color appeared. Finally, counterstaining was performed using Mayer's hematoxylin.
Statistical analyses. The data are presented as mean \pm standard error (SEM). Statistical comparisons between groups were performed using one-way analysis of variance (ANOVA) followed by Dunnett's test. Some data were also analyzed by the Student's t-test for paired or unpaired data. A p $<0.05$ was considered statistically significant.

\section{Results}

TMP inhibits the cell viability of A549 cells. TMP (molecular mass of $136.19 \mathrm{~g} / \mathrm{mol}$ ) was isolated, purified, and chemically synthesized (Fig. 1A). The effect of TMP on A549 cells has not been reported previously. First, we observed the influence of TMP (10 various concentration groups from 100 to $1000 \mu \mathrm{g} /$ $\mathrm{ml}$ ) on the proliferation of A549 cells using the MTT assay. Our results showed that TMP inhibited A549 cell proliferation in a time- and dose-dependent manner (Fig. 1B).

Based on the data from the MTT assay, we selected three different concentrations of TMP for further investigation: 200 (TMP200), 400 (TMP400) and $800 \mu \mathrm{g} / \mathrm{ml}$ (TMP800). As a positive control we used the COX inhibitor indomethacin at $200 \mu \mathrm{M}$ (IN) according to the data from the MTT assay (data not shown). Until now, the mechanism by which TMP affects A549 cell growth remained unclear. To examine whether TMP influenced cell cycle progression, we performed FACS, and the results revealed that TMP induced an accumulation of cells in the $\mathrm{G}_{0}-\mathrm{G}_{1}$ phase (from 55.06 to $72.61 \%$ ), and a concomitant depletion of cells in $\mathrm{S}$ phase (from 34.52 to $18.22 \%$ at $72 \mathrm{~h}$ ) (Table I and Fig. 1C). The effect was dose-dependent, consistent with the MTT results, and there was no significant difference between TMP800 and IN group. These data suggested that TMP could arrest A549 cell proliferation.

TMP inhibits the invasive ability of A549 cells. We selected $200 \mu \mathrm{g} / \mathrm{ml} \mathrm{TMP}$ to investigate the effects of TMP on A549 cell invasion. TMP at this concentration has no obvious influence on A549 cell viability according to the data from the MTT assay. After a 24-h incubation, the number of A549 cells adherent to the outer surface of the membrane was significantly decreased in the TMP-treated group compared to the control group (CON) (Fig. 2A), suggesting that TMP suppressed the invasive ability of A549 cells. Our studies showed that TMP exhibited an antiinvasive effect of A549 cells at a much lower concentration and much earlier time than its anti-proliferative effect.

Matrix metalloproteinases (MMPs) are a family of proteolytic enzymes that have been associated with tumor cell invasion and metastasis $(29,30)$. In contrast, the corresponding tissue inhibitor of metalloproteinases (TIMPs) negatively regulates the activity of MMPs and protects the basement membrane from proteolysis. 
A<smiles>Cc1nc(C)nc(C)n1</smiles>

2,3,5,6-Tetramethylpyrazine $(\mathrm{C} 8 \mathrm{H} 12 \mathrm{~N} 2)$ MW: $136.19 \mathrm{~g} / \mathrm{mol}$
C

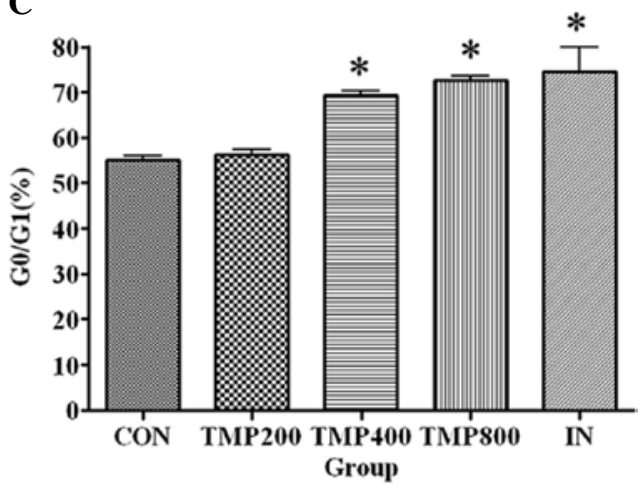

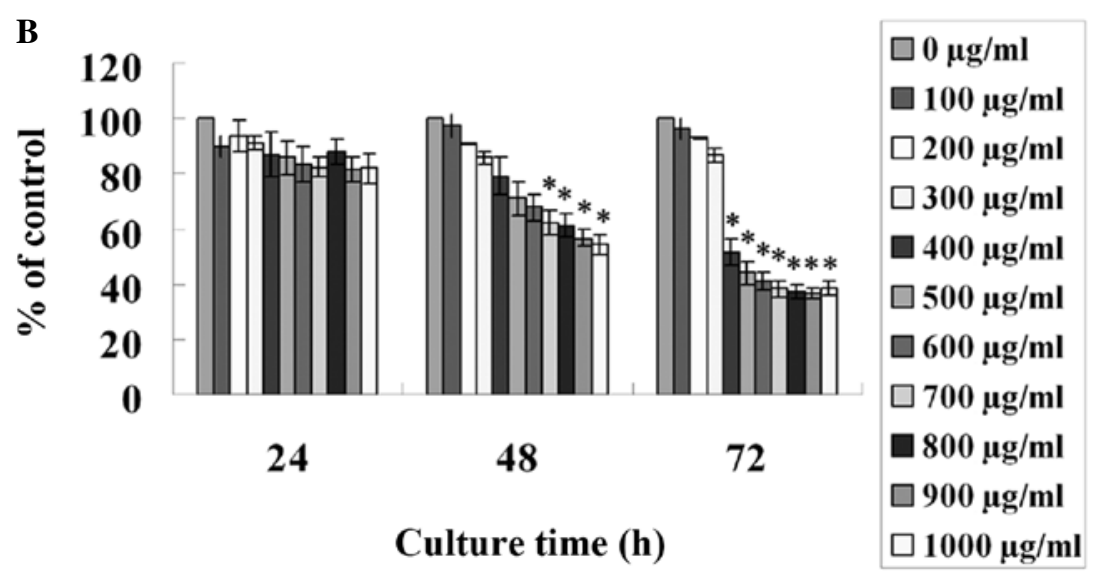

Figure 1. TMP inhibits cell proliferation and regulates cell cycle progression in A549 cells. (A) Chemical structure of TMP with a molecular weight of $136.19 \mathrm{~g} / \mathrm{mol}$. (B) TMP inhibits A549 cell proliferation in a dose- and time-dependent manner. The A549 cells were treated with the indicated doses of TMP for 24,48 and $72 \mathrm{~h}$ respectively. 3-(4,5-dimethylthiazol-2-yl)-2,5-diphenyltetrazolium bromide assays were performed. Results are expressed relative to the cell density of untreated cells. (C) TMP induces an accumulation of cells in $\mathrm{G}_{0}-\mathrm{G}_{1}$ phase in a dose-dependent manner. A549 cells $\left(1 \times 10^{6}\right)$ were treated with 200,400 and $800 \mu \mathrm{g} / \mathrm{ml} \mathrm{TMP} \mathrm{or}$ $200 \mu \mathrm{M}$ indomethacin (IN) for $72 \mathrm{~h}$, and the cell cycle was analyzed by FACS. Columns show the mean of three different experiments with six duplicates, and the SEM is indicated with bars. ${ }^{p}<0.05$ versus control.

The dysregulation of the balance between MMPs and TIMPs is associated with tumor cell invasion into the basement membrane, stroma, blood vessel, and subsequent metastasis. Increased MMP-2/TIMP-2 is not only implicated in the metastatic potential of cancer cells (31), but also closely associate with COX-2 activity (13). Here, we analyzed the activity of MMP-2 and its corresponding tissue inhibitor TIMP-2. Results showed that after a 24-h incubation, the activity of MMP-2/TIMP-2 in the supernatants from the TMP200, TMP400 and TMP800 groups were decreased compared with control. The inhibitory effect was dose-dependent, and there was no significant difference between TMP800 and IN group (Fig. 2B).

Effects of TMP on COX-2 in vitro. To investigate the molecular mechanisms involved in the anti-tumorigenic function of TMP, we evaluated the effect of TMP on COX-2 in A549 cells. First, we analyzed the protein expression level of COX-1 and COX-2 in A549 cells and NHLFs using Western blotting. Results showed that COX-1, a 'house-keeping' enzyme, was detected in both A549 cells and NHLFs. In contrast, COX-2, an induced enzyme, was detected in A549 cells, but not in NHLFs (Fig. 3A).

Using indomethacin as a known COX inhibitor, we observed the effect of TMP on COX-2 protein expression, enzyme activity and catalytic product formation. Results showed that indomethacin at $200 \mu \mathrm{M}$ significantly suppressed COX-2 expression and activity after a 24-h incubation. As a main catalytic product of COX-2, the level of $\mathrm{PGE}_{2}$ was also decreased in the medium of A549 cells treated with IN. Similar to the IN group, the COX-2 activity and $\mathrm{PGE}_{2}$ levels in the TMP group were also reduced significantly compared with the control group (Fig. 3C and D). However, there was no significant change of COX-2 expression level after treatment for $24 \mathrm{~h}$ with 200,400 or $800 \mu \mathrm{g} / \mathrm{ml}$ of TMP (Fig. 3B), suggesting that TMP has little influence on the protein expression of COX-2. Thus, the mechanism underlying the inhibitory effect on COX-2 likely differs between TMP and indomethacin.

TMP suppresses lung metastasis of A549 cells in metastatic nude mouse model and COX-2 expression in metastatic tumor nodules. To confirm the inhibitory effect of TMP on the invasion and metastasis of A549 cells in vivo, we utilized the metastatic nude mouse model. As shown in Fig. 4A, TMP-treated mice showed smaller visible metastatic pulmonary nodules compared to the control group. In addition, the average number of visible metastatic pulmonary nodules was significantly less in TMP-treated mice $(9 \pm 4)$ than in the control group $(23 \pm 11)$ $(\mathrm{p}<0.05)$ (Fig. 4B). H\&E stain further confirmed that both the number and the size of the metastatic lung nodules in the TMP group were significantly decreased compared to those in the control group (Fig. 4C). Immunohistochemistry analysis of the 
A
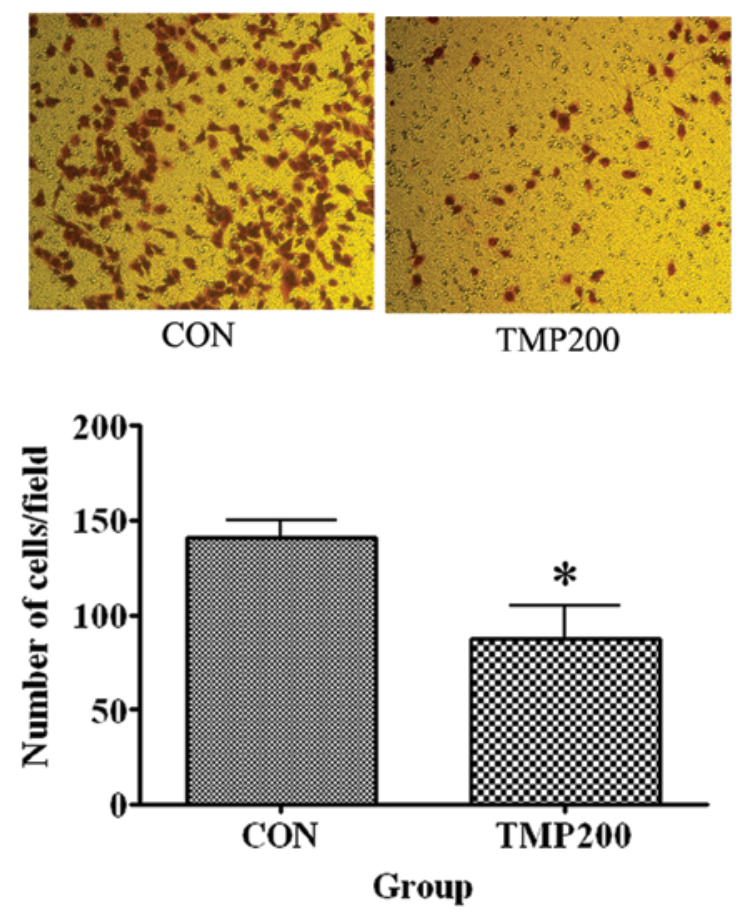

B

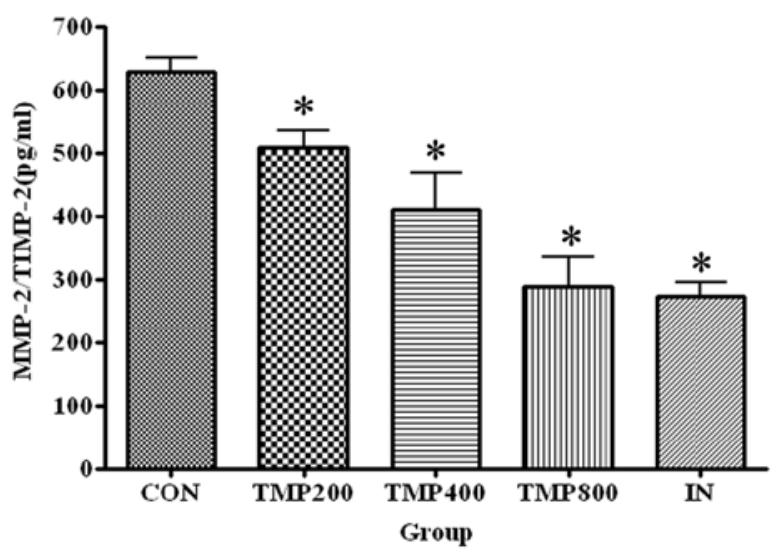

Figure 2. TMP inhibits A549 cells invasive ability by suppressing MMP-2/ TIMP-2 activity. (A) The number of invaded A549 cells in the TMP200 group was significantly smaller than that in CON group. A549 cells were seeded on 24-well transwell cell culture chambers at a density of $4 \times 10^{4}$ cells/well and cultured with or without $200 \mu \mathrm{g} / \mathrm{ml}$ TMP. After a $24-\mathrm{h}$ incubation, cells that invaded the lower surface were counted by light microscopy (crystal violet staining). Invaded cell numbers are the average count for six fields. (B) TMP reduced MMP-2/TIMP-2 activity in a dose-depended manner. After a 24-h incubation, the culture supernatants from each treated group were harvested, and MMP-2/TIMP-2 activity in the supernatants was determined by ELISA. Columns, mean from three different experiments with duplicates; bars, SEM. " $\mathrm{p}<0.05$ versus control.

metastatic lung nodules showed a reduction of COX-2 expression level in TMP treated group compared to that in the control group (Fig. 4D), which suggests that the anti-metastatic effect of TMP in vivo might be mediated through inhibiting the expression of COX-2, despite no difference observed in vitro. Except for the quickly released localized stimulus, no significant difference was observed in the diet, mental status, hair color, and luster of the nude mice between the TMP-treated group and the control group (Fig. 4E).

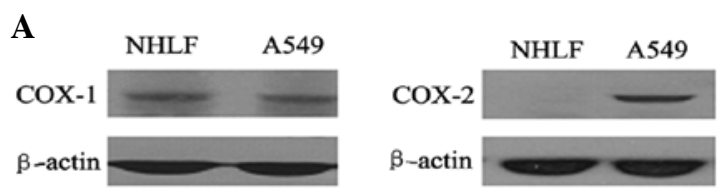

B

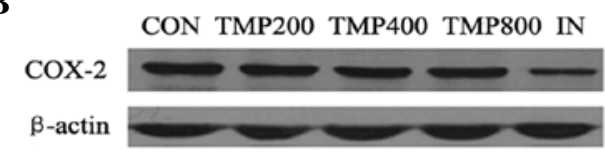

C

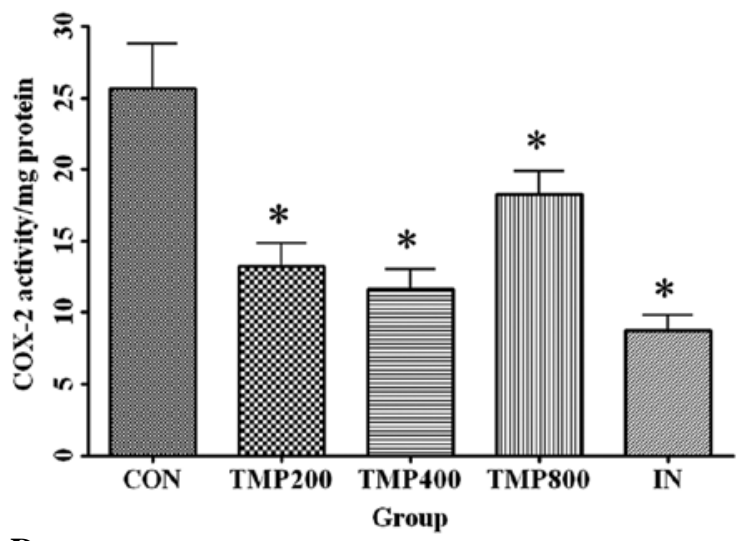

D

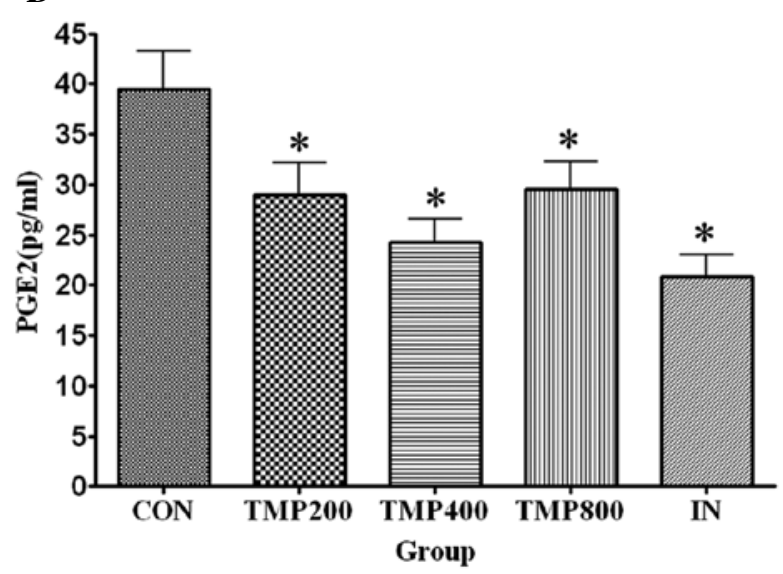

Figure 3. Effects of TMP on COX-2 in A549 cells. (A) A549 cells express COX-1 and COX-2 protein. After a 24-h incubation, A549 cells and NHLFs were harvested, and the expression of COX-1 and COX-2 were measured by Western blotting. (B) TMP has no obvious effect on COX-2 protein expression. After a 24-h incubation, cells from each treatment group were harvested, and then total protein was extracted for Western blotting. Results showed that COX-2 expression was reduced in IN group, while no obvious changes were observed in TMP-treated groups. (C) TMP inhibits COX-2 activity. Cells $\left(1 \times 10^{7}\right)$ from each treated groups were harvested after a 24-h incubation, and COX-2 activity was measured with a COX activity assay kit. (D) TMP inhibits $\mathrm{PGE}_{2}$ activity. Following a 24-h incubation, the accumulation of $\mathrm{PGE}_{2}$ in the culture medium was measured by specific radioimmunoassay. Columns, mean from three different experiments with duplicates; bars, SEM. "p $<0.05$ versus control.

\section{Discussion}

Natural compounds have long been used in cancer therapy and prevention. Recently, natural-product-based drugs are increasing due to new technologies and the current interest in their beneficial health effects. A substantial amount of evidence from human, animal model and cell line studies has shown that many herbal products used in traditional Chinese medicine can 
A
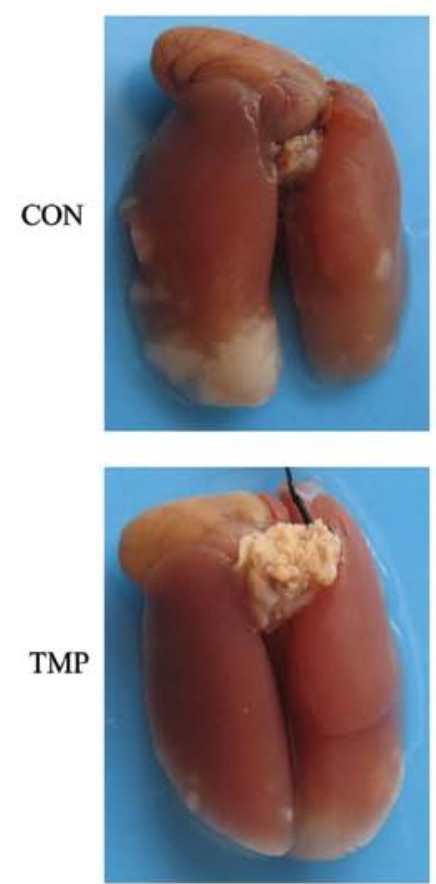
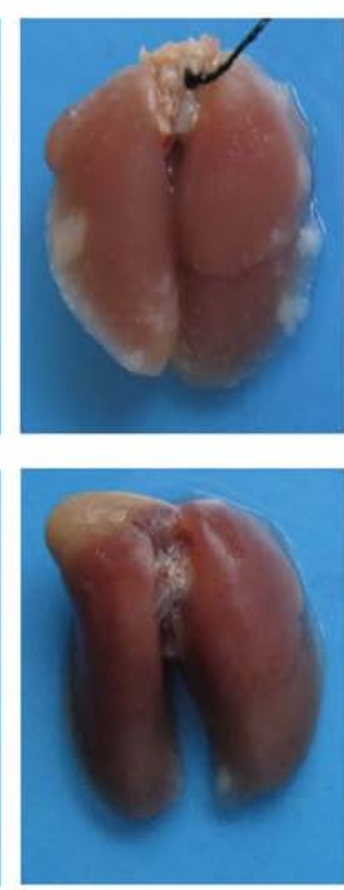

B

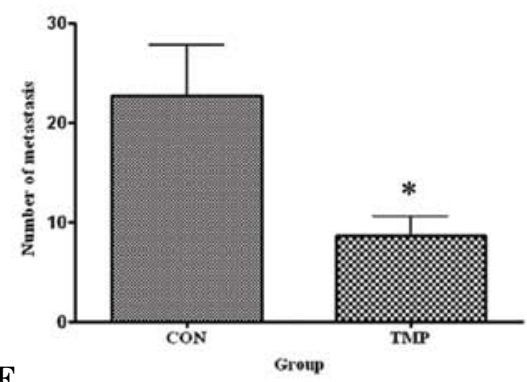

$\mathbf{E}$

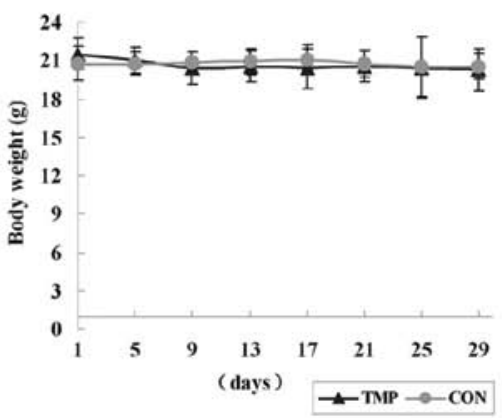

C
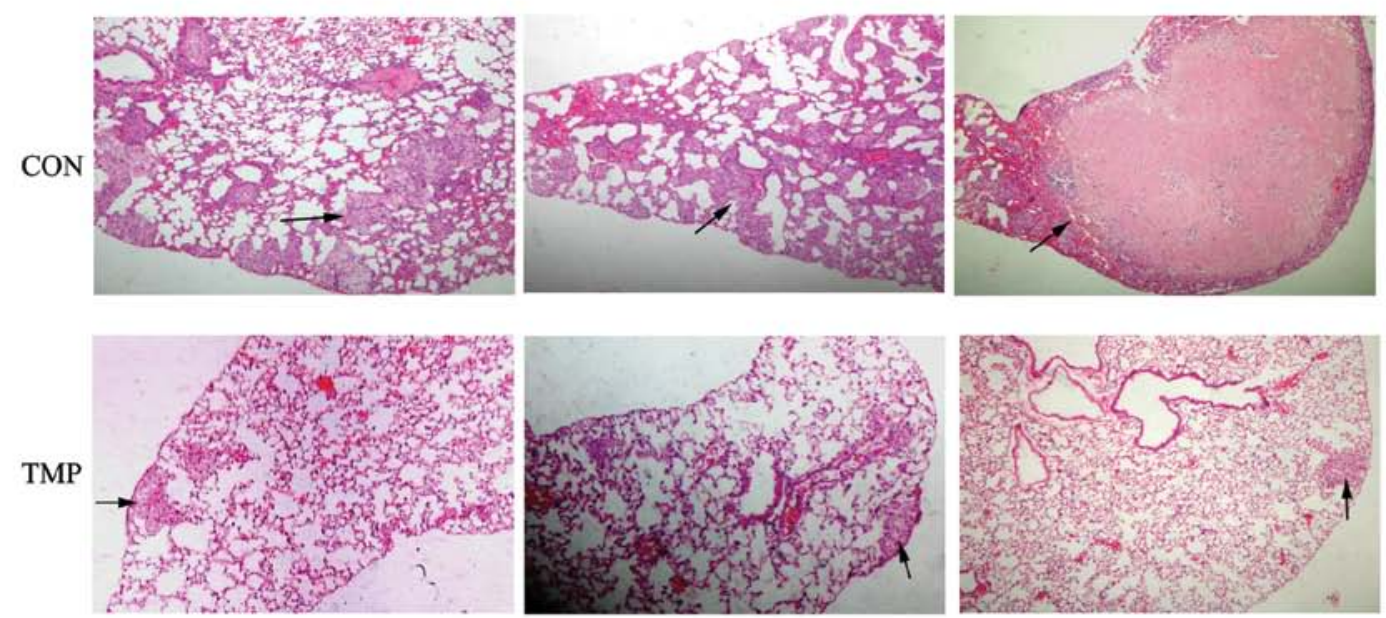

D
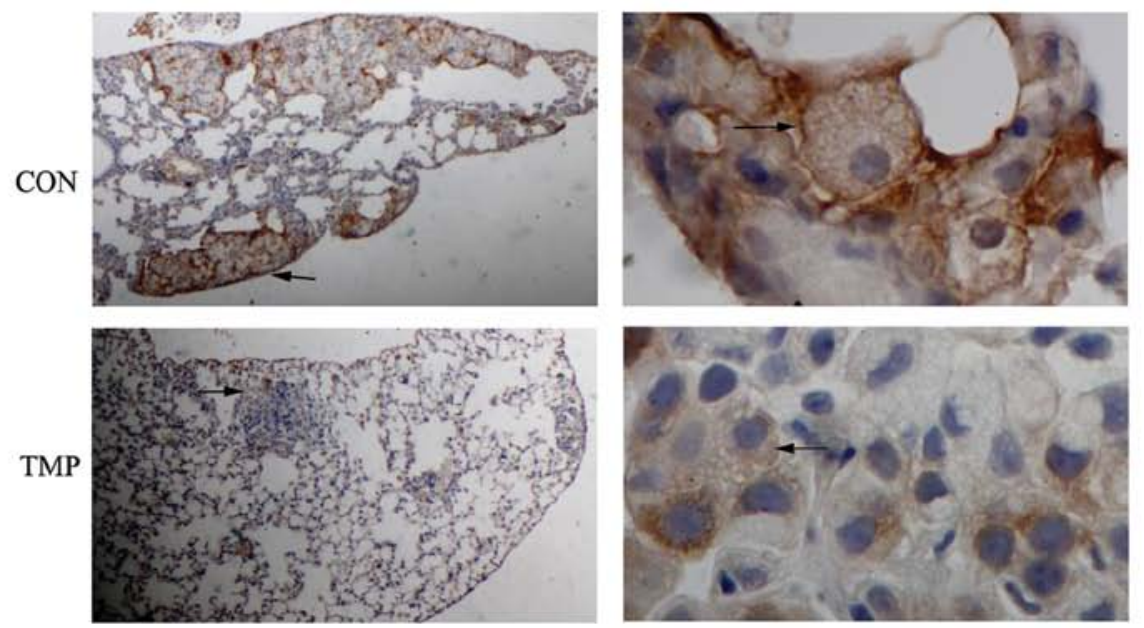

Figure 4. TMP suppresses lung metastasis of A549 cells through COX-2 pathway. (A) Photographs show lungs of A549 cell-bearing mice. (B) A549 cells (5x10 in a volume of $0.2 \mathrm{ml}$ serum-free DMEM medium) were injected into the lateral tail veins of 18 -week-old female BALB/c nude mice. Subsequently, TMP $(100 \mathrm{mg} / \mathrm{kg} / \mathrm{day})$ or isovolume physiological saline were administered by intraperitoneal injections daily. Mice were sacrificed and the number of metastasis in the lung surface was counted 29 days after the tumor cells were injected. (C) Representative photographs of H\&E staining for lung metastatic nodules (original magnification x40) of each group from two independent experiments. Both the number and size were decreased in the TMP group compared to the control group. (D) Immunohistochemical staining (brown) of COX-2 in lung metastatic nodules. Slides were incubated with 1:50 \pm 100 dilutions of the monoclonal mouse antiCOX-2 antibody at $4^{\circ} \mathrm{C}$ overnight. The density of COX-2 expression was observed using light microscopy. Original magnification $\mathrm{x} 40$ (left panel), or $\mathrm{x} 400$ (right panel). (E) TMP has little effect on mouse body weight. No significant difference between TMP-treated group (100 mg/kg/d) and the control group. Columns, mean $(\mathrm{n}=10)$; bars, SEM. " $\mathrm{p}<0.05$ versus control. 
exert anti-cancer effects. TMP, an effective component of the traditional Chinese medicine Chuanxiong, is commonly used to resolve embolism in clinic. In this study, we reported the novel anti-tumor effect of TMP on the human adenocarcinoma cell line A549 by targeting the COX-2 pathway. We comprehensively focused on the inhibitory effect of TMP on A549 cell proliferation, invasion and metastasis. Our research showed that TMP exhibited a dose- and time-dependent inhibitory effect on A549 cell proliferation by suppressing the cell progression from $\mathrm{G}_{0} / \mathrm{G}_{1}$ phase to $\mathrm{S}$ phase. TMP can decrease the invasive ability of A549 cells by inhibiting the activities of COX-2 and MMP-2/ TIMP-2. Furthermore, we showed that TMP can inhibit the in vivo metastatic growth of A549 cells in the nude mouse metastatic model. Both the number and the size of the metastatic lung nodules in the TMP group were significantly decreased compared to the control group. Unlike those anticancer agents that have adverse effects (32) or severe cytotoxicity in modern cancer chemotherapy, TMP presents low cytotoxicity yet has outstanding anti-invasion effect. In the nude mouse model, we found that TMP $(100 \mathrm{mg} / \mathrm{kg} / \mathrm{d})$ did not affect the body weight of the mice but showed a significant inhibitory effect on tumor metastasis. Thus, we propose that TMP may be a novel anticancer agent with limited toxicity.

Over the last decade, there is an increased interest in understanding the role of COX-2 in tumorigenesis. This interest was sparked by the fact that COX inhibitors reduced the mortality rate in certain cancer patients $(33,34)$. A recent epidemiological study of NSAID usage showed that daily intake of NSAIDs for at least 2 years was associated with a $68 \%$ reduction in the relative risk of lung cancer (35). Findings suggest that therapies targeting COX-2 may diminish the propensity for proliferation, invasion and metastases in NSCLC $(14,36,37)$. Here, we report for the first time that TMP can inhibit COX-2 activity in A549 cells and decrease $\mathrm{PGE}_{2}$ levels in the supernatant. Results from in vivo animal experiments also showed that the COX-2 expression in metastatic lung nodules in nude mice treated with TMP was obviously decreased compared with a physiological saline treated control group. These results suggest that the ability of TMP to inhibit COX-2 activity may contribute to its anticancer effect in lung adenocarcinoma. TMP when used at the $200 \mu \mathrm{g} / \mathrm{ml}$ showed no significant suppression of A549 cell proliferation, but had an inhibitory effect on A549 cell invasion and COX-2 activity. This result indicates that the reduced activity of COX-2 by TMP, at least at lower concentrations and earlier stages, contributed to the anti-invasion effect rather than the anti-proliferation effect. Notably, TMP had no obvious effect on COX-2 expression in A549 cells in vitro, whereas the COX-2 expression in metastatic lung nodules in the TMP-treated group was significantly decreased. This result indicated that TMP may regulate COX-2 expression through additional pathways in vivo. The mechanisms involved need further investigation.

The commonly used COX inhibitors consist classic NSAIDs and selective COX-2 inhibitors. About $25 \%$ of chronic NSAID users experience side effects such as gastrointestinal bleeding and renal toxicity $(18,38)$, which restrict their use as chemopreventive agents. Selective COX-2 inhibitors have reduced gastrointestinal related adverse events (39) but increased risk of cardiovascular diseases $(19,40)$. Selective COX-2 inhibitors may tip the natural balance between prothrombotic thromboxane A2 and antithrombotic prostacyclin, potentially increasing the possi- bility of a thrombotic cardiovascular event (41). On the contrary, the traditional use of TMP is for the treatment of cardiovascular diseases $(42,43)$ with proven efficacy and safety in the clinic. Thus, we speculate that the long-term use of TMP in chemoprevention and treatment of NSCLC, as a COX-2 inhibitor, could be beneficial for cardiovascular diseases instead of increasing their risk. Our findings suggest that TMP might serve as an effective agent for the treatment and chemoprevention of NSCLC by targeting COX-2 with much less toxicity.

MMP-2 has been implicated in the lymphatic and vascular invasion of NSCLC (44), and its overexpression correlates with an unfavorable outcome in patients with early-stage NSCLC (45). Our results showed that TMP significantly reduced the activity of MMP-2/TIMP-2 in the supernatants, suggesting that MMP-2/ TIMP-2 is one of the important pathways targeted by TMP in A549 cells. Several lines of evidence have suggested the involvement of COX-2 in the production and secretion of MMPs $(46,47)$. Treatment of non-small cell lung cancer cells with exogenous $\mathrm{PGE}_{2}$ significantly increased the expression of MMP-2 and invasion through Matrigel (13). Furthermore, inhibition of COX-2 has been reported to decrease invasion and MMP expression in lung cancer cells $(13,48)$. Thus, it is possible that there exists a direct link between COX-2 and MMP-2. However, underlying biologic mechanisms are not fully understood. Pan and coworkers (48) reported that a COX-2 selective inhibitor, NS398, can suppress MMP-2 expression in human lung cancer cells at a much higher concentration than the concentration needed to block enzymatic COX-2 activity. They speculated that the effect of NS398 on MMP-2 is not fully dependent on inhibition of COX-2 activity. Our studies showed that TMP inhibited the invasive ability of A549 cells, with a correlated decrease in the levels of MMP-2/ TIMP-2 and COX-2, which suggests a possible mechanism for the effect of TMP. However, it is difficult to state from our limited experiments whether the inhibitory effect of TMP on MMP-2/ TIMP-2 is direct or is mediated by the COX-2 pathway. Further evidence is needed to clarify the relationship between COX-2 and MMP-2/TIMP-2 in the inhibitory mechanism of TMP.

In conclusion, this preclinical study provides evidence for the first time that the inhibitory effect of TMP on invasion and metastasis of A549 cells is mediated, at least in part, through the inhibition of COX-2 activity. We also demonstrated that TMP inhibited the proliferation of A549 cells by regulating cell cycle progression, showing the potential of TMP as a chemopreventive as well as a therapeutic reagent. The significance of the inhibition of COX-2 as well as the other biological effects and mechanisms by which TMP inhibits NSCLC needs to be clarified in future studies.

\section{Acknowledgements}

We thank Dr Shan Wang for her advice and support. We are grateful to Dr Min Yu and Ms. Ying Xing for their writing assistance.

\section{References}

1. Vineis P, Alavanja M, Buffler P, Fontham E, Franceschi S, Gao YT, Gupta PC, Hackshaw A, Matos E, Samet J, Sitas F, Smith J, Stayner L, Straif K, Thun MJ, Wichmann HE, Wu AH, Zaridze D, Peto R and Doll R: Tobacco and cancer: recent epidemiological evidence. J Natl Cancer Inst 96: 99-10, 2004. 
2. Dubois RN, Abramson SB, Crofford L, Gupta RA, Simon LS, van De Putte LB and Lipsky PE: Cyclooxygenase in biology and disease. FASEB J 12: 1063-1073, 1998.

3. Smith WL, De Witt DL and Garavito RM: Cyclooxygenases: structural, cellular, and molecular biology. Annu Rev Biochem 69: 145-182, 2000.

4. Chandrasekharan NV, Dai H, Roos KL, Evanson NK, Tomsik J, Elton TS and Simmons DL: COX-3, a cyclooxygenase-1 variant inhibited by acetaminophen and other analgesic/antipyretic drugs: cloning, structure, and expression. Proc Natl Acad Sci USA 99: 13926-13931, 2002.

5. Achiwa H, Yatabe Y, Hida T, Kuroishi T, Kozaki K, Nakamura S, Ogawa M, Sugiura T, Mitsudomi T and Takahashi T: Prognostic significance of elevated cyclooxygenase 2 expression in primary, resected lung adenocarcinomas. Clin Cancer Res 5: 1001-1005, 1999.

6. Hasturk S, Kemp B, Kalapurakal SK, Kurie JM, Hong WK and Lee JS: Expression of cyclooxygenase-1 and cyclooxygenase-2 in bronchial epithelium and nonsmall cell lung carcinoma. Cancer 94: 1023-1031, 2002.

7. Hosomi Y, Yokose T, Hirose Y, Nakajima R, Nagai K, Nishiwaki Y and Ochiai A: Increased cyclooxygenase 2 (COX-2) expression occurs frequently in precursor lesions of human adenocarcinoma of the lung. Lung Cancer 30: 73-81, 2000.

8. Tsujii $\mathrm{M}$ and DuBois RN: Alterations in cellular adhesion and apoptosis in epithelial cells overexpressing prostaglandin endoperoxide synthase 2. Cell 83: 493-501, 1995.

9. Krysan K, Dalwadi H, Sharma S, Pold M and Dubinett S: Cyclooxygenase 2-dependent expression of survivin is critical for apoptosis resistance in non-small cell lung cancer. Cancer Res 64: 6359-6362, 2004.

10. Gately S: The contributions of cyclooxygenase-2 to tumor angiogenesis. Cancer Metastasis Rev 19: 19-27, 2000.

11. Leahy KM, Koki AT and Masferrer JL: Role of cyclooxygenases in angiogenesis. Curr Med Chem 7: 1163-1170, 2000.

12. Baratelli F, Lin Y, Zhu L, Yang SC, Heuze-Vourc'h N, Zeng G, Reckamp K, Dohadwala M, Sharma S and Dubinett SM: Prostaglandin E2 induces FOXP3 gene expression and T regulatory cell function in human CD4 ${ }^{+} \mathrm{T}$ cells. J Immunol 175 : 1483-1490, 2005.

13. Dohadwala M, Batra RK, Luo J, Lin Y, Krysan K, Pold M, Sharma S and Dubinett SM: Autocrine/paracrine prostaglandin E2 production by non-small cell lung cancer cells regulates matrix metalloproteinase-2 and CD44 in cyclooxygenase-2-dependent invasion. J Biol Chem 277: 50828-50833, 2002.

14. Dohadwala M, Luo J, Zhu L, Lin Y, Dougherty GJ, Sharma S, Huang M, Pold M, Batra RK and Dubinett SM: Non-small cell lung cancer cyclooxygenase-2-dependent invasion is mediated by CD44. J Biol Chem 276: 20809-20812, 2001.

15. Hida $T$, Yatabe $Y$, Achiwa H, Muramatsu H, Kozaki K, Nakamura S, Ogawa M, Mitsudomi T, Sugiura T and Takahashi T: Increased expression of cyclooxygenase 2 occurs frequently in human lung cancers, specifically in adenocarcinomas. Cancer Res 58: 3761-3764, 1998.

16. Tsubochi H, Sato N, Hiyama M, Kaimori M, Endo S, Sohara Y and Imai T: Combined analysis of cyclooxygenase- 2 expression with p53 and $\mathrm{Ki}-67$ in nonsmall cell lung cancer. Ann Thorac Surg 82: 1198-1204, 2006.

17. Huang M, Sharma S, Mao JT and Dubinett SM: Non-small cell lung cancer-derived soluble mediators and prostaglandin E2 enhance peripheral blood lymphocyte IL-10 transcription and protein production. J Immunol 157: 5512-5520, 1996.

18. Davies NM: Toxicity of nonsteroidal anti-inflammatory drugs in the large intestine. Dis Colon Rectum 38: 1311-1321, 1995.

19. Bresalier RS, Sandler RS, Quan H, Bolognese JA, Oxenius B, Horgan K, Lines C, Riddell R, Morton D, Lanas A, Konstam MA and Baron JA: Cardiovascular events associated with rofecoxib in a colorectal adenoma chemoprevention trial. N Engl J Med 352: 1092-1102, 2005

20. Kwan CY,Daniel EE and Chen MC: Inhibition of vasoconstriction by tetramethylpyrazine: does it act by blocking the voltage-dependent Ca channel? J Cardiovasc Pharmacol 15: 157-162, 1990.

21. Kwan CY: Plant-derived drugs acting on cellular $\mathrm{Ca}^{2+}$ mobilization in vascular smooth muscle: tetramethylpyrazine and tetrandrine. Stem Cells 12: 64-67, 1994.

22. Chen SX, Wang LX and Xing LL: [Effects of tetramethylpyrazine on platelet functions of advanced cases of lung carcinoma] Zhongguo Zhong Xi Yi Jie He Za Zhi 17: 531-533, 1997.
23. Zhang P, Pei Y and Qi Y: [Influence of blood-activating drugs on adhesion and invasion of cells in lung cancer patients].Zhongguo Zhong Xi Yi Jie He Za Zhi 19: 103-105, 1999.

24. Wan JY, Ye DY, Wu P, Zhang L, Gong X and Huang Y: [Effect of tetramethylpyrazine on lipopolysaccharides induced macrophage cyclo-oxidase- 2 expression and apoptosis of cardiac myocytes] Zhongguo Zhong Xi Yi Jie He Za Zhi 24: 906-911, 2004.

25. Zhang L, Bai M, Xia L and Gao Y: [Effects of ligustrazine on the expression levels of ET-1, COX-2 and CD54 in the lung tissue of rats with acute pulmonary embolism]. Acta Med Univ Sci Technol Huazhong 37: 31-34, 2008.

26. Fang HY, Lin TS, Lin JP, Wu YC, Chow KC and Wang LS: Cyclooxygenase-2 in human non-small cell lung cancer. Eur J Surg Oncol 29: 171-177, 2003

27. Hida T, Leyton J, Makheja AN, Ben-Av P, Hla T, Martinez A, Mulshine J, Malkani S, Chung P and Moody TW: Non-small cell lung cancer cycloxygenase activity and proliferation are inhibited by non-steroidal antiinflammatory drugs. Anticancer Res 18: 775-782, 1998.

28. Sharma SD, Meeran SM and Katiyar SK: Proanthocyanidins inhibit in vitro and in vivo growth of human non-small cell lung cancer cells by inhibiting the prostaglandin $\mathrm{E}(2)$ and prostaglandin $\mathrm{E}(2)$ receptors. Mol Cancer Ther 9: 569-580, 2010.

29. Kleiner DE and Stetler-Stevenson WG: Matrix metalloproteinases and metastasis. Cancer Chemother Pharmacol 43 (Suppl): S42-S51, 1999.

30. Stetler-Stevenson WG: Progelatinase A activation during tumor cell invasion. Invasion Metastasis 14: 259-268, 1994.

31. Herbst RS, Yano S, Kuniyasu H, Khuri FR, Bucana CD, Guo F, Liu D, Kemp B, Lee JJ, Hong WK and Fidler IJ: Differential expression of E-cadherin and type IV collagenase genes predicts outcome in patients with stage I non-small cell lung carcinoma. Clin Cancer Res 6: 790-797, 2000.

32. Heffeter P, Jungwirth U, Jakupec M, Hartinger C, Galanski M, Elbling L, Micksche M, Keppler B and Berger W: Resistance against novel anticancer metal compounds: differences and similarities. Drug Resist Updat 11: 1-16, 2008.

33. Giovannucci E, Rimm EB, Stampfer MJ, Colditz GA, Ascherio A and Willett WC: Aspirin use and the risk for colorectal cancer and adenoma in male health professionals. Ann Intern Med 121: 241-246, 1994.

34. Steinbach G, Lynch PM, Phillips RK, Wallace MH, Hawk E, Gordon GB, Wakabayashi N, Saunders B, Shen Y, Fujimura T, Su LK and Levin B: The effect of celecoxib, a cyclooxygenase-2 inhibitor, in familial adenomatous polyposis. $N$ Engl J Med 342: 1946-1952, 2000.

35. Harris RE, Beebe-Donk J and Schuller HM: Chemoprevention of lung cancer by non-steroidal anti-inflammatory drugs among cigarette smokers. Oncol Rep 9: 693-695, 2002.

36. Dubinett SM, Sharma S, Huang M, Dohadwala M, Pold M and Mao JT: Cyclooxygenase-2 in lung cancer. Prog Exp Tumor Res 37: 138-162, 2003.

37. Lee JM, Mao JT, Krysan K and Dubinett SM: Significance of cyclooxygenase-2 in prognosis, targeted therapy and chemoprevention of NSCLC. Future Oncol 3: 149-153, 2007.

38. Murray MD and Brater DC: Renal toxicity of the nonsteroidal antiinflammatory drugs. Annu Rev Pharmacol Toxicol 33: 435-465, 1993.

39. Silverstein FE, Faich G, Goldstein JL, Simon LS, Pincus T, Whelton A, Makuch R, Eisen G, Agrawal NM, Stenson WF Burr AM, Zhao WW, Kent JD, Lefkowith JB, Verburg KM and Geis GS: Gastrointestinal toxicity with celecoxib vs nonsteroidal anti-inflammatory drugs for osteoarthritis and rheumatoid arthritis: the CLASS study: a randomized controlled trial. Celecoxib Long-term Arthritis Safety Study. JAMA 284: 1247-1255, 2000.

40. Baron JA, Sandler RS, Bresalier RS, Lanas A, Morton DG, Riddell R, Iverson ER and Demets DL: Cardiovascular events associated with rofecoxib: final analysis of the APPROVe trial. Lancet 372: 1756-1764, 2008.

41. Jukic A, Kaliterna DM and Radic M: [Nonsteroidal anti-inflammatory drugs and the risk of cardiovascular diseases]. Reumatizam 57: 26-28, 2010 .

42. Liu SF, Cai YN, Evans TW, McCormack DG, Barer GR and Barnes PJ: Ligustrazine is a vasodilator of human pulmonary and bronchial arteries. Eur J Pharmacol 191: 345-350, 1990.

43. Wong KL, Chan P, Huang WC, Yang TL, Liu IM, Lai TY, Tsai CC and Cheng JT: Effect of tetramethylpyrazine on potassium channels to lower calcium concentration in cultured aortic smooth muscle cells. Clin Exp Pharmacol Physiol 30: 793-798, 2003. 
44. Brown PD, Bloxidge RE, Stuart NS, Gatter KC and Carmichael J: Association between expression of activated 72-kilodalton gelatinase and tumor spread in non-small-cell lung carcinoma. J Natl Cancer Inst 85: 574-578, 1993.

45. Passlick B, Sienel W, Seen-Hibler R, Wockel W, Thetter O, Mutschler W and Pantel K: Overexpression of matrix metalloproteinase 2 predicts unfavorable outcome in early-stage non-small cell lung cancer. Clin Cancer Res 6: 3944-3948, 2000.

46. Dempke W, Rie C, Grothey A and Schmoll HJ: Cyclooxygenase-2: a novel target for cancer chemotherapy? J Cancer Res Clin Oncol 127: 411-417, 2001.
47. Attiga FA, Fernandez PM, Weeraratna AT, Manyak MJ and Patierno SR: Inhibitors of prostaglandin synthesis inhibit human prostate tumor cell invasiveness and reduce the release of matrix metalloproteinases. Cancer Res 60: 4629-4637, 2000.

48. Pan MR, Chuang LY and Hung WC: Non-steroidal anti-inflammatory drugs inhibit matrix metalloproteinase-2 expression via repression of transcription in lung cancer cells. FEBS Lett 508: 365-368, 2001. 